\title{
Letramento acadêmico: dimensões mostradas e escondidas em rasuras em contexto digital
}

\author{
Tatiane Henrique Sousa Machado ${ }^{1}$ \\ Universidade Estadual de Maringá - UEM, Maringá, PR, Brasil \\ Cristiane Carneiro Capristano ${ }^{2}$ \\ Universidade Estadual de Maringá - UEM, Maringá, PR, Brasil \\ Neiva Maria Jung ${ }^{3}$ \\ Universidade Estadual de Maringá - UEM, Maringá, PR, Brasil
}

Resumo: O objetivo deste artigo foi analisar rasuras em artigos de opinião elaborados por acadêmicos, em contexto digital, verificando se elas poderiam sinalizar negociações (no sentido de Authier-Revuz, 1998) com dimensões escondidas das práticas de letramento acadêmicas (STREET, 2010). As rasuras analisadas emergiram de práticas escritas realizadas em uma disciplina de Leitura e Produção de Textos, de uma instituição privada. Fundamentados na perspectiva dos Letramentos Acadêmicos (LEA; STREET, 1998), com foco na problematização das dimensões escondidas, e numa visão enunciativa-discursiva de linguagem, verificamos que as rasuras apontavam para quatro negociações mais recorrentes ligadas: à seleção do léxico; à norma linguística; ao enquadramento do gênero; aos posicionamentos expressos nos textos. Nessas negociações, pôde-se ver o escrevente ora lidando com dimensões mostradas, mas opacas, como aquelas ligadas à norma linguística; ora com dimensões escondidas (não explicitadas na avaliação dos textos) das práticas letradas acadêmicas, como aquelas ligadas ao enquadramento do gênero e aos posicionamentos sociais.

Palavras-chave: Letramentos acadêmicos; Rasuras; Dimensões escondidas; Escrita.

Title: Academic literacy: shown and hidden features in erasures in digital context

Abstract: The objective of this paper was to analyze erasures in opinion articles made by undergraduate students, in digital context, verifying whether they could signal to negotiations (as in Authier-Revuz, 1998), with hidden features of academic literacy

\footnotetext{
${ }^{1}$ Doutoranda em Letras (Universidade Estadual de Maringá- UEM); Mestre em Letras - Universidade Estadual de Maringá - UEM, Docente da Universidade Paranaense - UNIPAR - Campus de Umuarama - PR. Orcid: https://orcid.org/0000-0002-4873-5239.

E-mail: tatiane@prof.unipar.br

${ }^{2}$ Doutora (Universidade Estadual de Campinas), Docente da Universidade Estadual de Maringá- UEM. Orcid: https://orcid.org/0000-0003-1225-5716.

E-mail: capristano1@yahoo.com.br

${ }^{3}$ Doutora (Universidade Federal do Rio Grande do Sul), Docente da Universidade Estadual de Maringá- UEM. Orcid: https://orcid.org/0000-0002-7249-7816.

E-mail: neivajung@yahoo.com.br
} 
practices (STREET, 2010). The analyzed erasures emerged from written practices during a Reading and Writing course in a private institution. Founded on the Academic Literacies perspective (LEA; STREET, 1998), with focus on the problematization of the hidden features, and also with a enunciative-discursive perspective of language, we verified that the erasures indicated to four more frequent types of negotiations, which are related: to lexicon selection; to linguistic norm; to the genre framework; to attitude expressed in the texts. On these negotiations, it was possible to observe writers dealing with shown but opaque features, as those related to linguistic norm, and hidden features (not explicit in the texts' evaluation) of the academic literate practices, as those related to the genre framework and to social attitude.

Keywords: Academic literacies; Erasures; Hidden features; Writing.

\section{O ponto de partida...}

O ensino superior no Brasil, conforme o Instituto Nacional de Estudos e Pesquisas Educacionais Anísio Teixeira (Inep), distribuiu-se, em 20174, em 2.448 instituições. Dentre essas, $87,9 \%$ eram privadas, $5,1 \%$ estaduais, $4,5 \%$ federais e $2,6 \%$ municipais. Nesse mesmo período, foram ofertadas mais de 10,7 milhões de vagas, das quais $92,4 \%$ eram de instituições privadas e apenas $7,6 \%$ de instituições públicas. As pesquisas do Inep também mostram que, em 2017, 3,2 milhões de alunos ingressaram no ensino superior, um crescimento de $8,1 \%$ em relação a 2016. O aumento do número de ingressantes entre 2016 e 2017 foi impulsionado, sobretudo, pela modalidade a distância: considerando-se tanto as instituições públicas quanto as privadas, observa-se uma variação positiva de $27,3 \%$ entre esses anos na modalidade a distância e uma variação de apenas $0,5 \%$ nos cursos presenciais.

Quando observado um intervalo maior de tempo, os dados do Inep também indicam crescimento do acesso ao ensino superior no país: no intervalo entre 2007 e 2017, na rede privada, a quantidade de alunos ingressantes cresceu 53,1\%; na rede pública, no mesmo período, o crescimento foi de $41,7 \%$. Também segundo as informações do censo mais recente do Inep, entre 2007 e 2017, o número de ingressantes variou positivamente nos cursos de graduação presencial - com taxa de 19,0\% - e mais de três vezes (226,0\%) nos cursos a distância. Ainda que passível de críticas graças ao modo como tem ocorrido, há um inegável avanço quantitativo no acesso à educação superior no Brasil nos últimos anos, mostrado por esses dados.

Esses dados também autorizam a supor que esse avanço trouxe consigo inúmeros desafios para todos os envolvidos com a educação em nível superior, dentre os quais se destaca, para nós, a necessária tarefa de lidar com a diversificação da população estudantil.

\footnotetext{
${ }^{4}$ As informações sobre o ensino superior foram coletadas no Censo da Educação Superior de 2017, último censo realizado no Brasil. Essas informações estão disponíveis em: http://download.inep.gov.br/educacao superior/censo superior/documentos/2018/censo da educ acao superior 2017-notas estatisticas2.pdf. Acesso em: 05 jan. 2019.
} 
O cenário político e educacional do país, no período avaliado pelo Inep, era relativamente positivo, no sentido de indicar uma disposição política para manter e expandir a necessária participação de jovens de diferentes estratos sociais, com diferentes histórias, desejos e expectativas, na educação superior do Brasil.

Vários programas e políticas públicas criados ou mantidos nesse período, que visavam à inclusão de grupos historicamente excluídos desse nível educacional, contribuíram para essa salutar diversificação da população estudantil, como o Programa Universidade para Todos (Prouni) ${ }^{5}$, o Programa de Estímulo à Reestruturação e ao Fortalecimento das Instituições de Ensino Superior (Proies) ${ }^{6}$, o Programa de Apoio a Planos de Reestruturação das Universidades Federais (REUNI) ${ }^{7}$, o Sistema de Seleção Unificada (Sisu) ${ }^{8}$, o novo Fundo de Financiamento ao Estudante do Ensino Superior (FIES) ${ }^{9}$, a Lei das Cotas nas Instituições Federais $^{10}$, o Plano Nacional de Assistência Estudantil (PNAES) ${ }^{11}$.

${ }^{5}$ O Programa Universidade para Todos - PROUNI - foi instituído pela Lei no 11.096, de 13 de janeiro de 2005. É um programa do Ministério da Educação, criado pelo Governo Federal, cuja finalidade é ofertar bolsas de estudo integrais e parciais (50\%) em instituições privadas de educação superior. Para mais informações, conferir o site http://siteprouni.mec.gov.br/(Último acesso em 08/02/2019).

${ }^{6} \mathrm{O}$ Programa de Estímulo à Reestruturação e ao Fortalecimento das Instituições de Ensino Superior (Proies) foi instituído pela Lei no 12.688, de 18 de julho de 2012, com o objetivo de assegurar condições para a continuidade das atividades de entidades mantenedoras de instituições de ensino superior integrantes do sistema de ensino federal, por meio da aprovação de plano de recuperação tributária e da concessão de moratória de dívidas tributárias federais. Para mais informações, conferir o site http://portal.mec.gov.br/proies-apresentacao (Último acesso em 08/02/2019).

7 O Programa de Apoio a Planos de Reestruturação das Universidades Federais - REUNI - foi instituído pelo Decreto no 6.096, de 24 de abril de 2007, com a meta de dobrar o número de alunos nos cursos de graduação em dez anos, a partir de 2008, e permitir o ingresso de 680 mil alunos a mais nos cursos de graduação das Instituições Federais de Educação Superior. Para mais informações, conferir o site http://reuni.mec.gov.br/ (Último acesso em 08/02/2019).

${ }^{8}$ O Sistema de Seleção Unificada (Sisu) foi criado pelo Ministério da Educação em 2010, com o objetivo de substituir o vestibular tradicional nas instituições públicas de educação superior, assegurando gratuidade a todos os estudantes de escolas públicas e utilizando os resultados do Enem, combinados a um conjunto de ações afirmativas, como critério de seleção dos estudantes. Para mais informações, conferir: http://www.sisu.mec.gov.br/. (Último acesso em 08/02/2019).

${ }^{9} \mathrm{O}$ Fundo de Financiamento ao Estudante do Ensino Superior - FIES - foi criado pela Lei no 10.260, de 12 de julho de 2001 e profundamente redefinido pela Lei no 12.202, de 14 de janeiro de 2010 Para mais informações, conferir: http://fies.mec.gov.br/. (Último acesso em 08/02/2019).

10 Lei no 12.711, de 29 de agosto de 2012 (Lei das Cotas). A lei estabelece que as instituições federais de educação superior vinculadas ao Ministério da Educação reservarão, em cada concurso seletivo para ingresso nos cursos de graduação, por curso e turno, no mínimo 50\% (cinquenta por cento) de suas vagas para estudantes que tenham cursado integralmente o ensino médio em escolas públicas e que, no preenchimento destas vagas, $50 \%$ (cinquenta por cento) deverão ser reservados aos estudantes oriundos de famílias com renda igual ou inferior a 1,5 salário-mínimo (um salário-mínimo e meio) per capita.

${ }^{11}$ O Plano Nacional de Assistência Estudantil (Pnaes), que apóia a permanência de estudantes de baixa renda matriculados em cursos de graduação presencial das Instituições Federais de Educação 
Principalmente em razão desses programas e políticas públicas, existe uma população plural circulando hoje pelas universidades brasileiras, trazendo consigo vivências sócio-históricas diversificadas, incluindo as vivências com a escrita. No ingresso dessa população no ambiente universitário, essas vivências se mesclam com outras, produzindo encontros e desencontros. No tocante às vivências com a escrita, por exemplo, as práticas de escrita valorizadas no meio universitário ora se aproximam, ora se distanciam das experiências anteriores dos ingressantes. Nesse jogo entre aproximação e distanciamento, quando a escrita dos ingressantes não corresponde ao esperado pelas práticas letradas universitárias, essa não correspondência tem sido interpretada, em geral, como fracasso, atribuído, de forma frequente, exclusivamente a esses acadêmicos.

Existe um ideário que confere ao acadêmico ingressante na universidade o domínio de certas práticas de escrita, dada a seleção realizada pelo próprio vestibular. Tal visão conduz ao apagamento da diversidade: diferentes estudantes, com diferentes formações escolares e sociais, com diferentes histórias, desejos e expectativas, convivem no ensino superior e, desses estudantes distintos, é exigida a circulação por práticas letradas com as quais estão, eventualmente, pouco familiarizados. Somam-se a isso o fato de as orientações dadas por docentes sobre essas práticas pouco familiares tomarem como pressuposto uma imagem equivocada do que é conhecido pelos estudantes sobre essas práticas, imagem que, em geral, não corresponde com a realidade vivida pelos acadêmicos. O resultado é que, não raro, os acadêmicos são culpabilizados por seus resultados insatisfatórios na produção escrita, em função dos conflitos entre as práticas letradas dos acadêmicos e as exigidas pelas práticas acadêmicas universitárias.

Em oposição a tal ideário, pesquisas no campo dos Novos Estudos do Letramento (STREET, 2014; LEA, STREET, 1998) propiciam uma importante discussão sobre a escrita como prática social: portanto, a escrita vista como variando em função do contexto sóciohistórico de seu uso, dos gêneros discursivos nos quais se realiza e da cultura na qual emerge. Nessa perspectiva, consideram-se as práticas de escrita interligadas a relações de poder, as quais produzem diferentes efeitos sobre os sujeitos imersos nessas relações, efeitos nem sempre previsíveis. Com base nesses autores, é possível afirmar que o descompasso entre as vivências com a escrita dos acadêmicos e as exigidas pelas práticas acadêmicas universitárias - entre o antes e o depois de serem aprovados no vestibular se deve, pelo menos em parte, às chamadas práticas institucionais de mistério (LILLIS, 1999) ou, ainda, às dimensões escondidas das práticas letradas acadêmicas (STREET, 2010), noções que, fundamentalmente, se referem a não explicitação, nessas práticas, de critérios avaliativos da produção escrita do acadêmico ou, ainda, à distância entre as expectativas

Superior (IFES), foi instituído pelo Decreto no 7.234, de 19 de julho de 2010. Para mais informações, conferir: http://portal.mec.gov.br/pnaes. (Último acesso em 08/02/2019). 
institucionais e o que o acadêmico efetivamente consegue produzir em suas práticas escritas (KOMESU; GAMBARATO, 2013).

Partindo dessas pesquisas e de outras no campo dos Novos Estudos do Letramento - como em Lea e Street (1998) e Street (2014) - , objetivamos investigar neste artigo rasuras em textos redigidos em contexto digital, presentes especialmente em artigos de opinião produzidos por acadêmicos, verificando em que medida essas rasuras podem sinalizar negociações (no sentido de Authier-Revuz, 1998) com dimensões escondidas das práticas letradas efetivadas em contexto acadêmico universitário. Trata-se, portanto, de, por meio da análise das rasuras, refletir sobre encontros e desencontros entre práticas de escrita trazidas pelos acadêmicos e aquelas requeridas pela universidade.

Para tanto, foram analisados enunciados produzidos durante uma aula de Leitura e Produção de Textos, por acadêmicos do primeiro ano de cursos superiores de Odontologia e Sistemas de Informação ${ }^{12}$, de uma universidade privada do interior do Paraná, turma na qual uma das autoras deste artigo atua como docente e como pesquisadora ${ }^{13}$. As rasuras são aqui consideradas "como local privilegiado para a observação da relação sujeito/linguagem e dos caminhos trilhados pelo escrevente para manifestação do seu projeto de dizer" (MACHADO e CAPRISTANO, 2016, p. 339). Entendemos que a análise das rasuras nos textos dos acadêmicos, produzidas em contexto digital, permite problematizar o caráter técnico atribuído a essa escrita, demonstrando, em alguma medida, o modo como se edifica o diálogo dos escreventes com dimensões escondidas (STREET, 2010) das práticas letradas das quais passam a participar.

Este artigo foi organizado da seguinte forma: de início, discutimos mais pormenorizadamente as noções de Letramentos Acadêmicos e de dimensões escondidas, noções epistemológicas fundamentais para o entendimento que orientou a análise desenvolvida neste artigo. Na sequência, apresentamos o enquadramento teórico a partir do qual interpretamos nosso objeto de investigação: as rasuras. Depois disso, detalhamos os passos metodológicos e, em seguida, analisamos rasuras identificadas no material eleito para análise, relacionando-as às dimensões escondidas. Por fim, tecemos algumas considerações finais sobre o que foi possível verificar sobre o diálogo mostrado nas rasuras entre vivências sócio-históricas dos acadêmicos ingressantes e dimensões escondidas das práticas letradas efetivadas em contexto universitário.

\footnotetext{
${ }^{12}$ As turmas de Odontologia e Sistemas de Informação cursam, juntas, a disciplina de Leitura e Produção de Textos ( $2 \mathrm{~h} / \mathrm{a}$ ) presencialmente, por isso, foram selecionadas para esta pesquisa.

13 O presente estudo é parte de um projeto de doutoramento aprovado pelo Comitê de Ética em Pesquisa envolvendo Seres Humanos da Universidade Paranaense - UNIPAR, (Parecer n. 2.675. 458).
} 


\section{Letramentos acadêmicos}

Lea e Street (1998) desenvolveram, no Reino Unido, um modelo denominado Letramentos Acadêmicos, ancorando-se nos Novos Estudos do Letramento (New Literacy Studies) de Street (1984), Gee (1989), o qual serviu e serve de base para inúmeras pesquisas no Brasil, tais como: Marinho (2010), Fiad (2011), Corrêa (2011) e Komesu e Gambarato (2013), dentre outras. A noção de letramentos acadêmicos, originalmente, foi criada visando ao estudo de letramentos em nível superior; no entanto, como destacam Komesu \& Fischer (2014), esse conceito também se aplica ao período da pré-escola ao ensino médio. Ou seja, a noção não é usada para tratar apenas de um período no tempo e de um limite no espaço (o tempo e o espaço do ensino superior) ou de temas e disciplinas exclusivas desse tempo e desse espaço, mas, sim, dos efeitos de um conjunto de discursos institucionais mais amplos sobre como ocorrem certas práticas de leitura e escrita.

Nessa perspectiva, como antecipamos, a escrita é vista como prática social e, nesse sentido, a compreensão de seu funcionamento depende do contexto sócio-histórico no qual emerge, dos gêneros discursivos nos quais se realiza e da cultura a qual pertence; a escrita é, assim, "um conjunto de práticas sociais", associado "com diferentes domínios de vida" (BARTON; HAMILTON; IVANIC, 2000, p. 8), logo vinculado a diferentes interesses e finalidades. Ademais, entende-se que as práticas de escrita não ocorrem desvinculadas de relações de poder entre pessoas, instituições e identidades sociais, entendimento que visa a colocar em destaque a "natureza institucional daquilo que conta como conhecimento em qualquer contexto acadêmico específico" (KOMESU; FISCHER, 2014, p. 479). Trata-se, pois, de entender que escrever não é apenas uma habilidade técnica, ligada à superfície da competência linguística dos acadêmicos, nem se reduz a um processo de assimilação cultural, mas estaria no nível da epistemologia, da autoridade e da contestação (LEA \& STREET, 1998; KOMESU; FISCHER, 2014).

Street (2010) e Lillis (1999) reconhecem que, nas práticas de escrita acadêmicas, embora alguns aspectos esperados para a produção escrita sejam explicitados pelo docente, existem outros aspectos que não são, permanecendo, em certo sentido, "ocultos". Esse fenômeno é nomeado como "práticas do mistério" (LILLIS, 1999) ou "dimensões escondidas" (STREET, 2010), noções que, neste estudo, serão consideradas como sinônimos possíveis. Essas noções buscam chamar a atenção para a existência de práticas letradas consideradas comuns à cultura acadêmica que não seriam explicitadas pelo docente - representante da voz da instituição - para o escrevente. Tais condutas, conforme assume Lillis (1999), dificultariam a participação do aluno como atuante nas práticas escritas acadêmicas.

Para Street (2010, p. 543), as dimensões escondidas abarcariam "critérios que aqueles autores, investidos de poder no âmbito acadêmico, utilizam na avaliação dos trabalhos produzidos" e que o aluno, não familiarizado com essa cultura, não saberia ou 
entenderia. Como exemplo, Street (2010) destaca a existência de questões constituintes da redação de um artigo científico como prática social acadêmica, as quais se supõem que os alunos deveriam saber responder e que ele reconhece como dimensões escondidas, como: qual é o enquadramento do gênero, sua finalidade ou objetivos, a contribuição ou para quê escrevem, sua voz como autores ou quem são no texto, o ponto de vista ou como querem ser reconhecidos pelos leitores do seu texto, as marcas linguísticas que poderiam reconhecer para fazerem referências ao contexto, ao método, e, por fim, a dimensão da estrutura do artigo.

Em seus estudos, Street (1984) e Lillis (1999) também assumem que o espaço sociodiscursivo da escola e da universidade configura-se, em geral, como monológico, já que a voz do docente (representante da voz da instituição) predomina. Existem poucos espaços e tempos para a intermediação, entre docentes e alunos, das expectativas que cercam as atividades com a escrita. Esquece-se, também, como afirma Lillis (1999), que fornecer acesso aos saberes acadêmicos não pode se limitar a permitir o ingresso do aluno na universidade. Para ela, seria necessário um investimento na disponibilização de recursos simbólicos e na explicitação das demandas da instituição. Logo, o eventual descompasso entre a expectativa da instituição com o que o aluno consegue responder se daria, sobretudo, por falhas na (ou ausência de) explicitação do que a instituição espera dele.

Sem negar que, de fato, a falha e a ausência de explicitação possam ser um problema, é necessário também considerar que "o significado de uma enunciação nunca coincide com o conteúdo puramente verbal: as palavras ditas estão impregnadas de coisas presumidas e de coisas não ditas" (PONZIO, 2016, p. 93). Nesse sentido, embora não tenha sido o objetivo deste artigo problematizar os limites do que uma "explicitação do que se espera" pode ter para a eficácia das práticas letradas acadêmicas, não ignoramos que esses limites existam, já que supomos ser próprio das relações de poder instauradas nas práticas escritas a pluralidade de efeitos de sentidos.

É por não ignorar que os sentidos estão dissimulados nas práticas escritas em geral e, em particular, nas práticas escritas universitárias, que julgamos possível avaliar o eventual descompasso entre as vivências com a escrita dos acadêmicos e as exigidas pelas práticas acadêmicas universitárias por meio da consideração das práticas institucionais de mistério (LILLIS, 1999), ou, ainda, das dimensões escondidas das práticas letradas acadêmicas (STREET, 2010), noções aqui tomadas, como antecipado, como eventuais sinônimos.

Assim, propomo-nos, conforme Street (2010) e Fiad (2011), a desafiar o "não" que aparece em afirmações como "não são letrados", "não escrevem bem", "não leem", "não se dedicam às atividades propostas", e olhar nas rasuras o "sim", "os usos concretos das práticas letradas" (BARTON; HAMILTON; IVANIC, 2000) como sinais de suas trajetórias em práticas letradas acadêmicas, a fim de legitimá-las, por meio da análise das negociações explicitadas por elas, que sinalizaria, a nosso ver, em alguma medida, dimensões escondidas 
da escrita de um artigo de opinião. Em função desse objetivo mais geral, na próxima seção, apresentamos a concepção de rasura assumida neste artigo.

\section{Escreve, apaga, altera: olhando para o gesto de rasurar}

As rasuras foram tomadas como objeto de estudo primeiro pela Crítica Genética. Neste campo, elas são consideradas pistas ou marcas que o autor do texto literário deixa no decorrer de seu trabalho de criação (SILVA, 2010, p. 147). Esses pesquisadores analisam manuscritos e rascunhos, observando apagamentos, sobreposições, notas, riscos e traços deixados pelo escritor no processo de construção de seu texto. Cabe ao geneticista debruçar-se sobre traços e fissuras "que revelam a posteriori índices de fragilidades e incompletudes do discurso" (BIASI, 2002, p. 222, grifos do autor). No campo dos estudos sobre a linguagem, especialmente na investigação da produção escrita de crianças, pesquisadores como Calil e Felipeto (2001), Capristano (2013), Machado (2014) e Machado e Capristano (2016), dentre outros, também se dedicam a analisar rasuras manuscritas, a partir de diferentes propósitos e perspectivas teóricas.

Com o advento da escrita feita diretamente no computador, alguns geneticistas passaram a observar a necessidade de alteração dos estudos na Crítica Genética, em busca de incorporar as pegadas deixadas pelo escritor nos processadores de texto - como o Microsoft Word ou WordPerfect. Nesses processadores, o escritor pode colar, recortar, substituir, excluir, sem, contudo, deixar marcas visíveis no seu texto final. Essas ações, no entanto, podem ser recuperadas por ferramentas oferecidas pelos próprios processadores. A atual aposta geneticista é a de que o rascunho digital formado pelo registro das ações "apagadas" constituiria "um documento de uma riqueza cognitiva sem precedentes" (BIASI, 2008, n.p).

Inspirados, pelo menos em parte, nessa aposta, entendemos que, assim como nas rasuras manuscritas, as ações de colar, recortar, substituir e excluir, armazenadas pelos processadores de texto, pode ser um rico material para investigar diferentes possibilidades de construção de um projeto de dizer que se mostram para o sujeito escrevente. Partindo da ideia de rascunho digital de Biasi (2008), reconhecemos que a produção textual por meio do Google docs ${ }^{14}$, por exemplo, permite ao pesquisador analisar rasuras, ou seja, caminhos

${ }^{14}$ O Google Docs é um pacote de aplicativos do Google. As ferramentas do Google Docs funcionam de forma síncrona e assíncrona e, nesse sentido, permitem acessar dados em nuvens e off-line por meio de aplicativos de extensão instalados diretamente do Google. Esse pacote de aplicativos compõe-se de um processador de textos, um editor de apresentações, um editor de planilhas e um editor de formulários. Essas ferramentas permitem aos usuários criar e editar documentos online, ao mesmo tempo colaborando, em tempo real, com outros usuários (informações recolhidas de https://pt.wikipedia.org/wiki/Google Docs, último acesso em 09/02/2019). 
abandonados, projetos de dizer substituídos, que auxiliariam a compreender o processo de inserção dos acadêmicos nas práticas letradas solicitadas na universidade.

Como nos estudos de rasuras em textos manuscritos, consideramos que o exame de rasuras nos textos produzidos em contexto digital, aqui representadas por caminhos abandonados e/ou projetos de dizer substituídos e armazenados pelos processadores de textos, pode contribuir para uma melhor compreensão da relação sujeito-linguagem. Para nós, esses caminhos abandonados e/ou projetos de dizer substituídos não formam um amontoado de lixo virtual/digital descartável; não são insucessos, escoriações ou enganos imotivados, mas, sim, fatos constituintes do modo de enunciação escrito no ambiente digital, sinais que mostram de forma particular a heterogeneidade do discurso (AUTHIERREVUZ, 1998, 2011) pelo qual circulam os escreventes em suas práticas escritas. As rasuras seriam, nesse sentido, manifestações de heterogeneidade mostrada, funcionando à semelhança das marcas de hesitação e de retoque descritas por Authier-Revuz (1998). Tratam-se, como nesses casos, de momentos visíveis de negociação do sujeito com os diferentes outros que o constituem: outros dizeres, outros discursos, outras variedades linguísticas, outros saberes, outros gêneros discursivos etc.

A partir da apropriação dos preceitos teóricos de Authier-Revuz (1998, 2011, dentre outros) e de como esses preceitos foram interpretados em trabalhos como Capristano (2013), Machado (2014) e Machado e Capristano (2016), supomos que a rasura, tanto a manuscrita quanto a que emerge em contexto digital, indiciaria uma marca da divisão enunciativa do escrevente, uma vez que representaria "uma aparente negociação do 'um' com os outros que o constituem e determinam a emergência dos enunciados que produz" (CAPRISTANO, 2013, p. 666).

Com base no reconhecimento desses pressupostos, vejamos como funcionam as rasuras em contexto digital, a partir da observação do excerto apresentado na Figura 1:

Figura 1 - Exemplo de gesto de apagamento/inserção na rasura digital

Mas-o-que está levande países-a restringir a-entrada-em-seu-territérie-de-q̨uem-preeisa-Nem tudo é tão simples, pois Aabrigar imigrantes geralmente causa desconforto e até mesmo violência entre

Fonte: Banco de dados dos pesquisadores

Na Figura 1, um escrevente, num primeiro gesto de escrita, digita: Mas o que está levando países a restringir a entrada em seu território de quem precisa. Abrigar imigrantes geralmente causa desconforto e até mesmo violência [...]. Todavia, posteriormente, apaga Mas o que está levando países a restringir a entrada em seu território de quem precisa e 
insere Nem tudo é tão simples, pois, produzindo Abrigar imigrantes geralmente causa desconforto e até mesmo violência.

Nas rasuras produzidas em contexto digital, como na Figura 1, parece haver, quase sempre, um gesto triplo que envolve digitar, apagar e inserir. Outras vezes, mais raras, esse gesto é dual, conforme o exemplo apresentado na Figura 2:

Figura 2 - Exemplo de gesto de apagamento na rasura digital moradia, plano de saúde, salário e refeições. Mesmo sabendo das dificuldades do Brasil, ainda temos condições melhores do que o povo refugiado. Se existisse uma fiscalização para que não ocorresse cases de escravidão como ocorrem não só no Brasil mas sim na maioria dos paises que recebem esse povo, daria ainda mais certo.

Fonte: Banco de dados dos pesquisadores

Na Figura 2, o escrevente digitou e, depois, fez o apagamento de todo o último período do parágrafo, sem, contudo, substituí-lo por outro. Para o presente artigo, não serão analisados gestos duais, ou seja, aqueles nos quais não se identifica a operação de substituição. Analisaremos exclusivamente as rasuras que envolvem a tríplice ação de digitar-apagar-inserir. Na próxima seção, caracterizamos os passos metodológicos que permitiram descrever e explicar esse tipo de rasura.

\section{Construindo as condições da análise...}

Em função dos objetivos do presente artigo, analisaremos 13 excertos retirados de um banco de textos constituído para a realização de uma pesquisa maior. Esse material foi coletado, como adiantado, a partir de uma proposta de produção de textos realizada em 2017, com 60 acadêmicos que, à época, cursavam uma disciplina intitulada Leitura e Produção de Textos que compõe a grade curricular do 1 o ano dos cursos de Sistemas de Informação e Odontologia de uma universidade particular do interior do Paraná. Na referida disciplina, foi solicitada a escrita de um artigo de opinião, em grupos de 4 integrantes. Essa solicitação foi feita com o comando apresentado no Quadro 1: 
Quadro 1-Comando de Produção Textual

\section{PROPOSTA DE ATIVIDADE}

Após lerem os dois artigos de Opinião da Folha de São Paulo ${ }^{15}$ e outros do Umuarama llustrada, discutam sobre o tema: É legítimo barrar a imigração em nome da segurança e do desenvolvimento econômico? Posteriormente, escrevam, EM GRUPO (CONFORME COMPARTILHAMENTO), UM ARTIGO DE OPINIÃO que poderia ser publicado no jornal local, no qual vocês se posicionem sobre o tema.

\section{ORIENTAÇÕES:}

Digitar neste arquivo

Todos os integrantes do grupo podem alterar partes do texto ou inseri-las;

Vocês devem defender UM PONTO DE VISTA sobre o tema;

Escrever de acordo com a norma padrão;

Pode utilizar informações dos textos, mas pesquisem outras para enriquecer seu texto e para formar uma opinião com argumentos;

Dê um título ao texto e insira os nomes dos acadêmicos e respectivos RA e curso. Posteriormente, inicie a escrita (times new roman, tamanho 12).

Fonte: Banco de dados dos pesquisadores

A docente responsável pela disciplina também dedicou duas horas/aulas para a discussão da arquitetura do gênero "artigo de opinião", discussão que esteve fundamentada na leitura de um capítulo do livro Português: contexto, interlocução e sentido, da Editora Moderna, organizado por Abaurre, Abaurre e Pontara (2008), capítulo este que justamente tratava da definição do gênero. Após essa etapa de discussão, os grupos de escreventes foram organizados aleatoriamente, reunindo-se 4 integrantes, totalizando 15 grupos.

A escrita em grupo foi realizada por meio de uma ferramenta da Google denominada Google Docs (cf. nota 11). Nesta ferramenta, um mesmo arquivo pode ser compartilhado com um número grande de pessoas que pode modificar e editar o arquivo de forma simultânea, salvando automaticamente todas as alterações realizadas em tempo real. Todas as pessoas com as quais o arquivo é compartilhado podem, também, ter acesso a todas as alterações. Ou seja, a redação de textos no Google Docs permite que os usuários vejam todo o histórico de alterações (apagamentos, inserções, destaques etc.) realizado durante a escrita do texto.

\footnotetext{
${ }^{15}$ Trata-se de dois artigos de opinião, com posicionamentos contrários sobre o tema "É legítimo barrar a imigração em nome da segurança e do desenvolvimento econômico?", intitulados "Fantoches do Globalismo (Durval Lourenço Pereira) e Percepção Equivocada (Adriana Erthal Abdenur; Maria Beatriz Bonna Nogueira). Esses artigos foram publicados na coluna Tendências $e$ Debates, do Jornal Folha de São Paulo, no dia 04 de fevereiro de 2017.
} 
A docente responsável pelas turmas organizou 15 arquivos, com o comando acima mencionado, e compartilhou cada arquivo, exclusivamente, com o seu referido grupo. Foram dados aos alunos 20 dias para a redação do artigo de opinião. A docente salientou que os acadêmicos poderiam reunir-se presencialmente, mas também poderiam trabalhar cada um de sua casa ou cidade, sendo, contudo, exigida a participação de todos os integrantes na redação do artigo. Após 20 dias, dos 15 grupos, 2 grupos não realizaram a atividade. Foram coletados, portanto, 13 artigos de opinião.

Para o desenvolvimento da análise, foi realizada a leitura dos 13 artigos de opinião dos 13 grupos e a leitura dos históricos de alterações, nos quais se podiam visualizar os apagamentos, inserções, destaques etc. feitos por cada um dos integrantes de cada grupo. Feita a análise do histórico de alterações, foi observado que, em quatro artigos de opinião, não havia nenhuma alteração, ou seja, os acadêmicos pareceram ter escrito "num fôlego só". Supomos que, provavelmente, eles escreveram o artigo no papel ou em outro arquivo e, posteriormente, copiaram e colaram para o arquivo compartilhado, impossibilitando, assim, o acesso ao histórico de alterações e, consequentemente, o acesso às rasuras.

Restaram 09 artigos de opinião, nos quais foram identificadas 196 rasuras que envolviam a tríplice ação de digitar-apagar-inserir. Para a organização e análise dessas rasuras, consideramos o que chamaremos aqui de dimensões mostradas do gênero artigo de opinião, ou seja, os saberes explicitamente agenciados pela docente para solicitar a redação do artigo. Dentre esses saberes, destacam-se: (a) as informações presentes no comando da atividade; (b) a seleção da temática que deveria ser discutida nos artigos de opinião; (c) as orientações feitas oralmente para o desenvolvimento da atividade; e, por fim, (d) as informações e as orientações contidas no capítulo do livro organizado por Abaurre, Abaurre e Pontara (2008), supramencionado, capítulo explorado pela docente responsável pela disciplina para explicar o que era o gênero artigo de opinião.

Sem a pretensão de fazer uma apresentação exaustiva desse material, que fugiria ao escopo deste artigo, pode-se afirmar que as orientações dadas nessas diversas ações que circundaram a elaboração do artigo de opinião pelos acadêmicos visavam a estabelecer os contornos do gênero em questão. Já no comando, há informações sobre a esfera de circulação do gênero (a esfera "jornalística"), seu estilo (texto que requer um "ponto de vista" e que deve ser redigido em "norma padrão"), seu tema (texto que obriga a exploração de um tema atual, de interesse para leitores de um jornal), sua estrutura composicional (o texto precisa ter "título" e agenciar diferentes "argumentos"). Essas informações se repetem, em seu todo ou em parte, nas orientações orais dadas pela docente, nas quais 
foram acrescidas informações sobre a necessidade de produzir um texto "criativo" e "coerente" 16 .

Essas informações são, também, explicitamente discutidas no capítulo do livro organizado por Abaurre, Abaurre e Pontara (2008). Neste capítulo de livro, o artigo de opinião é definido como "um gênero discursivo claramente argumentativo, que tem por objetivo expressar o ponto de vista do autor que o assina sobre alguma questão relevante, geralmente controversa" (ABAURRE, ABAURRE e PONTARA, 2008, p. 623). Essas autoras destacam que, tradicionalmente, esse gênero circula por jornais, em especial, em colunas específicas, destinadas a diferentes tipos de leitores, reforçando a afirmação já contida no comando para a produção textual. Destacam, também, que, estruturalmente, esses gêneros não são fixos, mas precisam ter algumas "partes" que desempenhariam algumas funções, tais como: (a) título, cuja função seria resumir a ideia central do artigo e chamar a atenção do leitor; (b) um primeiro parágrafo, cuja finalidade seria fazer uma contextualização da questão a ser analisada; (c) um segundo parágrafo no qual o autor expressaria seu posicionamento valorativo, por meio do uso de adjetivos e de advérbios; (d) terceiro e quarto parágrafos, nos quais seriam apresentados respostas e argumentos que sustentariam a análise; e (e) uma conclusão contendo a análise final do articulista e, portanto, a defesa da tese do artigo. Abaurre, Abaurre e Pontara (2008) ainda salientam que a linguagem e o padrão de formalidade desta são definidos pelo espaço de circulação e o perfil de leitores, contudo, normalmente, segundo as autoras, no artigo de opinião prima-se pela norma culta da língua portuguesa.

Todas essas informações compõem, a nosso ver, as dimensões mostradas do gênero artigo de opinião, tal como ele foi apresentado para esses alunos, nesse contexto sóciohistórico. Não são, portanto, dimensões universais, mas um conjunto de orientações explícitas cuja finalidade foi a de circunscrever alguns limites dentro dos quais os acadêmicos deveriam produzir seu texto. Deve-se notar que esse conjunto de orientações em pouco ou quase nada difere das práticas de ensino de gênero que, em geral, são levadas a cabo em escolas de ensino fundamental e médio, amplamente descritas e analisadas em pesquisas no campo da Linguística Aplicada (cf. por, exemplo, HILÁ, 2008; CRISTÓVÃO, 2010; OHUSHI; BARBOSA, 2011; CERUTTI-RIZZATTI, 2012). Nesse sentido, parece haver, nessa proposta de produção de textos, uma continuidade entre as práticas letradas acadêmicas no ensino fundamental e médio e as práticas letradas acadêmicas desenvolvidas no ensino superior, ou seja, as dimensões mostradas da prática aqui tomada como material de análise são muito semelhantes àquelas que se veem em outros contextos e tempos de escolarização.

\footnotetext{
${ }^{16}$ Como mencionado, uma das autoras deste artigo atua como docente e como pesquisadora na instituição na qual foram coletados os dados analisados. As informações sobre as orientações orais dadas aos acadêmicos referem-se à memória que a docente tem do período em que foi realizada a atividade.
} 
Com base na consideração dessas dimensões mostradas, passamos a interrogar os dados na tentativa de ver respondidas as seguintes questões: (a) Quais negociações se mostram nas rasuras digitais identificadas nos artigos de opinião redigidos pelos acadêmicos? (b) Em que medida essas negociações podem sinalizar dimensões escondidas das práticas letradas acadêmicas?

Norteadas por essas questões, pudemos verificar uma ampla variedade de negociações. Dentre essas, quatro tipos mostram-se mais recorrentes. São eles: (a) negociações ligadas à seleção do léxico; (b) negociações ligadas à norma linguística; (c) negociações ligadas ao enquadramento do gênero; e (d) negociações ligadas aos posicionamentos expressos nos textos. Na próxima seção, sem pretensão de encerrar a discussão sobre essas diferentes negociações mostradas pelas rasuras em contexto digital, exploramos cada uma delas, mostrando como e/ou em que medida elas podem estar relacionadas a dimensões escondidas das práticas letradas acadêmicas (STREET, 2010).

\title{
Rasuras digitais: quais negociações se mostram?
}

Um primeiro tipo de negociação identificado de forma mais recorrente no conjunto de enunciados considerados para a análise mostra-se como alterações de natureza estilística ligadas à seleção lexical, como exemplifica o excerto apresentado na Figura 3:

Figura 3 - Rasura digital: seleção lexical

\begin{abstract}
Países e seus habitantes, que não estão submersos em guerras, estão sendo vendadeso alienados por uma massa esmagadora que diz que refugiados acusa imigrantes fugitivos de guerras estão invadindo seus países para tomar-lhes tudo: empregos, escolas, conforto ou até quem sabe suas vidas. Não vêem que pode ser eles mesmos os causadores de toda essa imigração, devido a interferências em suas culturas.
\end{abstract}

Fonte: Banco de dados dos pesquisadores.

Inicialmente, os escreventes registram ${ }^{17}$, em seu primeiro gesto, Países e seus habitantes, que não estão submersos em guerras, estão sendo vendados por uma massa esmagadora que diz que refugiados de guerras estão invadindo [...]. Depois, fazem modificações, deletando os trechos "vendados" e "diz que refugiados", substituindo-os por "alienados" e "acusa imigrantes fugitivos". O texto final pode ser lido como: Países e seus

\footnotetext{
${ }^{17} \mathrm{Na}$ análise, faremos referência a "escreventes", para respeitar o fato de a redação do artigo ter sido feita de forma colaborativa. Consideramos, pois, que, mesmo que a alteração tenha sido proposta por apenas um dos integrantes do grupo, ela foi aceita como uma decisão do grupo e, por isso, sinaliza uma visão de escrita desse grupo.
} 
habitantes, que não estão submersos em guerras, estão sendo alienados por uma massa esmagadora que acusa imigrantes fugitivos de guerras estão invadindo [...].

Ao substituírem "diz" por "acusar", "refugiados de guerras" por "imigrantes fugitivos de guerras", "vendados" por "alienados", bem como não fazerem os acertos sintáticos que garantiriam adequação à "norma padrão" para a substituição pretendida - a saber: Países $e$ seus habitantes, que não estão submersos em guerras, estão sendo alienados por uma massa esmagadora que acusa imigrantes fugitivos de guerras de estarem invadindo [...] os escreventes dão-nos indicações de que foram afetados por uma preocupação com o peso valorativo da seleção lexical para a construção da argumentação, ou seja, mostram-se como estando sensíveis para o fato de as palavras não serem neutras e terem um papel fundamental para a arquitetura do gênero artigo de opinião.

Num artigo de opinião, a seleção lexical funciona, de fato, como um importante recurso para o estabelecimento dos efeitos de sentido desejados pelos escreventes, na busca da articulação e do detalhamento de suas teses. A escolha do léxico não é, portanto, algo irrelevante ou banal e pode contribuir sobremaneira para construção do projeto de dizer dos escreventes. Nesse sentido, sem dúvida, a seleção do léxico é, também, um dos critérios para a avaliação da qualidade da produção escrita dos escreventes: no artigo de opinião, selecionar um léxico não condizente com as teses defendidas e refutadas é motivo para uma avaliação negativa.

Considerando as dimensões mostradas da prática docente da qual o excerto em tela é resultado, pode-se observar que a importância da seleção lexical para a construção da argumentação não foi mencionada. As orientações orais da docente e o comando de produção textual fornecido aos acadêmicos, bem como o capítulo de livro no qual a docente se fundamentou para explicar as características do gênero artigo de opinião, não explicitaram que a seleção do léxico contribui para a produção de sentido do texto e para a arquitetura da argumentação. Essa importante dimensão do gênero artigo de opinião não foi "mostrada", ela esteve "escondida": tomou-se por pressuposto que os acadêmicos conseguiriam lidar com ela e, consequentemente, dominariam as escolhas lexicais para esse gênero.

$\mathrm{Na}$ tríplice ação de digitar-apagar-inserir do excerto em análise, veem-se os escreventes negociando com essa dimensão escondida do gênero artigo de opinião que os fazem enfrentar a necessidade de lidar com o peso valorativo das palavras. Independente da adequação das seleções lexicais feitas na versão final proposta pelos escreventes - se correspondem ou não às expectativas da docente e, consequentemente, da instituição - , há, no excerto, pistas de um encontro entre as vivências com a escrita dos escreventes e as vivências valorizadas nessa prática de escrita. Portanto, pode-se dizer que há uma negociação com dimensões escondidas, mas uma negociação que nasce da partilha de expectativas. 
Um segundo tipo de negociação identificado de forma mais recorrente no conjunto de enunciados considerados para a análise mostra-se como alterações, também de natureza estilística, ligadas à norma linguística prevista para o gênero, como exemplifica o excerto apresentado na Figura 4:

Figura 04 - Rasura digital: norma linguística

VariosVários fatores levam as pessoas abandonar seu paispaís de origem onde
vivem para se mudar para outro, falta de emprego, catastrofe, atentados, dificuldades financeiras sao
algusnalguns fatores que influenciam e muito.
O movimento imigratorio vem crescendo cada vez mais com isso alguns paisespaises aceitam a
imigracaoimigração legal para ter uma maomão de obra barata e é uma chance de recomeço de vida para
esse povo que teve que abandonar sua terra natal.
Entretanto novos povos sao um motivo de preocupaçaøpreocupação para o estado na questao de
seguranca.PaisesPaises que aceitam novas entradas de pessoas como mulcumanasmuçulmanas
estaøestão propentespropensos a ter alguns conflitos, com isso paisespaíses acoledoresacolhedores
devem ter um modelo de regras a ser seguidas por esses imigrantes para naønão haver protestos com o
governo.
A chegada de diferentes povos faz o com que os paisespaises tenha uma diversidade de povos,
raças, culturas, culinariaculinária, e costumes, mostrando que querem uma boa forma de vida em um bom
paispais.

Fonte: Banco de dados dos pesquisadores

Nesse excerto, os escreventes realizam uma espécie de "varredura", dedicando-se, quase exclusivamente, a reparar desvios ortográficos e gráficos. Na tríplice ação de digitarapagar-inserir, os escreventes fazem modificações (a) na acentuação gráfica, inserindo acentos nas palavras vários, país (2x), países (2x) e culinária; (b) na concordância verbal, mudando o verbo vive para vivem; (c) na digitação, modificando algusn para alguns; e (d) na seleção de grafemas e inserção de sinal gráfico indicativo de nasalização (til), nas palavras imigração, mão, preocupação e não. Os escreventes também modificam a posição de um grafema e a seleção de outro, na palavra muçulmanas, e inserem um grafema em acoledores, registrando, em seu gesto final, acolhedores. Por fim, vemos também uma alteração entre propentes/propensos, mais opaca, provavelmente também uma correção da digitação.

Nesse excerto, dois fatos chamam a atenção. Por um lado, a convivência das alterações acima descritas com (a) a ausência de alterações nas palavras catástrofe e imigratório - que, apesar da "varredura" feita pelos escreventes, permaneceram sem acento gráfico; (b) a ausência do sinal gráfico indicativo de nasalização (til), nas palavras são (2x) e questão; e, por fim, (c) a falta de concordância em os países tenha (antepenúltima linha do excerto). Por outro lado, destaca-se que as várias rasuras presentes no excerto são apenas reiterações do mesmo, já que os escreventes mostram-se sensíveis, predominantemente (com exceção de apenas um único caso envolvendo concordância verbal), para aspectos gráficos e ortográficos do seu enunciado. 
Entendemos que, neste tipo de rasura, quase estritamente gráfico-ortográfico, reside uma dimensão "escondida" do letramento acadêmico, qual seja: a opacidade de orientações como "Escrever de acordo com a norma padrão" e/ou primar-se "pela norma culta da língua portuguesa", diretrizes, respectivamente, presentes no comando de produção textual fornecido pela docente e no capítulo teórico no qual se sustentaram as discussões sobre as características do gênero artigo de opinião.

Dito de outro modo, embora instruções explícitas sobre a adequação à norma "padrão" ou "culta"18 tenham sido fornecidas aos acadêmicos, essas instruções mostradas não são transparentes e/ou óbvias. As rasuras colocam em evidência que a experiência dos acadêmicos ingressantes com a norma "padrão" e/ou "culta" pode não corresponder à experiência esperada pelas práticas acadêmicas. As rasuras sinalizam uma sensibilidade dos escreventes para quase estritamente aspectos gráfico-ortográfico de seu enunciado, enquanto, para a docente e a instituição que ela representa, existem outros aspectos envolvidos no que se compreende por escrita adequada à norma "padrão" e/ou "culta", como a adequação da pontuação, da regência, a diversificação dos elementos encadeadores do texto etc. Há, pois, um descompasso entre expectativas (acadêmico $X$ instituição/docente) do que seria a escrita de um artigo de opinião em consonância com a norma padrão e/ou culta.

Esse tipo de rasura, embora comum e necessária, dada a natureza da prática de escrita analisada (realizada em contexto universitário, com a exigência de constituir-se como um texto de cunho formal que poderia ser publicado em um jornal local), coloca em cena uma grande e quase exclusiva preocupação com características sintáticas e formais do modo de enunciação escrito; uma conduta de objetivação da escrita como mera técnica. Portanto, não se trata apenas de um ato de "correção", mas de uma negociação com valores historicamente construídos sobre como deve ser a escrita acadêmica de um artigo de opinião passível de ser publicado em um jornal e lido por diferentes públicos, feito no âmbito de um processo avaliativo de uma disciplina que problematiza e explora a leitura e produção de textos.

Por fim, resta observarmos que a convivência das alterações acima descritas com a ausência de alterações nas palavras catástrofe e imigratório - que, apesar da "varredura" feita pelos escreventes permaneceram sem acento gráfico; (b) a ausência do sinal gráfico indicativo de nasalização (til), nas palavras são (2x) e questão; e, por fim, (c) a falta de

18 Embora, muitas vezes, as noções de "norma culta" e "norma padrão" sejam usadas como sinônimos, alguns autores entendem que elas se referem a realidades distintas. De acordo com Marcos Bagno (2002, p. 185), por exemplo, "de um lado, temos a norma-padrão lusitanizante, ideal de língua abstrato, usado como verdadeiro instrumento de repressão e policiamento dos usos linguísticos; do outro, temos as diversas variedades cultas, usos reais da língua por parte das classes sociais urbanas com escolaridade superior completa." 
concordância em os países tenha (antepenúltima linha do excerto) é sinal de que a imagem dos escreventes do que seria importante para a escrita acadêmica de um artigo de opinião redigido para o processo avaliativo de uma disciplina voltada para a leitura e produção de textos não atua o tempo todo. Parecem existir regiões privilegiadas para a emergência dessas rasuras e também das negociações que elas indiciam. Uma discussão sobre essa problemática, no entanto, foge ao escopo deste artigo.

Um terceiro tipo de negociação identificado de forma mais recorrente no conjunto de enunciados considerados para a análise mostra-se como alterações ligadas ao enquadramento do gênero, como exemplifica o excerto apresentado na Figura 5:

Figura 05 - Rasura digital: enquadramento do gênero

Não, a A imigração é algo que produz mudanças sociais profundas tanto de onde ela vem de origem quanto na que ela chega, esperando seu acolhimento. A imigração acontece por diversos motivos, como buscas por um vida em melhores condições, busca por paz. Porém ela faz com que os residentes locais tenham diferentes formas de reações, pois muitos acreditam que os recém-chegados apresentam uma certa ameaça para sua cultura e economia.

Fonte: Banco de dados dos pesquisadores

Na rasura do trecho inicial desse excerto, é possível observar a oscilação dos escreventes entre dois gêneros discursivos: a resposta argumentativa e o artigo de opinião. Essa interpretação ancora-se no gesto inicial da estrutura frasal recusada: Não, a imigração é algo que produz [...], substituída por uma declaração: A imigração é algo que produz [...]. No primeiro caso, uma resposta direta ao comando para produção textual, no qual constava a seguinte pergunta: "É legítimo barrar a imigração em nome da segurança e do desenvolvimento econômico?". No segundo, um início mais prototípico de um artigo de opinião.

Sabemos que as respostas argumentativas são bastante frequentes nas práticas de letramento acadêmico, nas diferentes etapas de escolarização, como estratégia didática. Elas são usadas em processos avaliativos e em exercícios desenvolvidos em sala de aula, em diferentes disciplinas. É razoável supor, então, que os acadêmicos ingressantes no contexto universitário estejam bastante familiarizados com esse gênero escolar, que ressoa nessa rasura. Nela, vemos sinalizada uma negociação com o enquadramento do gênero como "artigo de opinião" e "resposta ao docente", que coloca em primeiro plano uma dimensão escondida dos gêneros acadêmicos e, por extensão, das práticas letradas acadêmicas: o fato de os gêneros discursivos nascerem e vicejarem no diálogo com outros gêneros, em um universo de relações intergenéricas, no sentido de Corrêa (2003 e 2006).

Desde que ficou estabelecido, pelos Parâmetros Curriculares Nacionais (PCNs), que os gêneros discursivos deveriam ser o eixo organizador do ensino e da aprendizagem do 
Português, nas práticas letradas acadêmicas, nos diferentes níveis de escolarização, tem-se feito um investimento no ensino dos gêneros discursivos voltado para seus aspectos mais modelares. Em outras palavras, nessas práticas, a preocupação tem sido, quase sempre, com a adequação do texto produzido pelo aluno ao modelo de gênero discursivo fornecido pelo professor, adequação que "se traduz, na maioria dos casos, na mera verificação dos aspectos formais presentes nesses textos" (CÁLIS, 2015, p. 13). Nesse modo de ensinar, deixa-se de lado o caráter processual e dinâmico dos gêneros, para colocar em primeiro plano sua dimensão estável - que deveria ser vista sempre como relativamente estável, como afirma Bahktin (1992).

Baseado em Corrêa (2003), Cális (2015) argumenta que o apego excessivo das práticas pedagógicas atuais aos aspectos mais estáveis dos gêneros esconderia o fato de os gêneros discursivos não serem formas linguísticas fechadas em si mesmas, já que estariam na dependência de relações intergenéricas. Essas relações marcariam "o inescapável convívio entre as esferas da atividade humana" (CÁLIS, 2015, p. 13) e determinariam regiões de contato entre os gêneros que tornariam suas fronteiras muito tênues (cf., também, CORRÊA, 2003 e 2006). São justamente as regiões de contato, as fronteiras tênues, as afinidades, as coexistências entre os gêneros "resposta argumentativa" e "artigo de opinião", apagadas e escondidas nas práticas letradas acadêmicas em razão de um excessivo investimento nas dimensões modelares desses gêneros, que provocam a emergência da rasura apresentada na Figura 5.

A alteração que vemos nessa rasura, longe de ser resultado de insucessos ou enganos imotivados, sinaliza que esses escreventes estiveram sensíveis para as semelhanças não explicitadas entre esses dois gêneros, vistas na estrutura composicional, no estilo, nos conteúdos temáticos e, também, em seus endereçamentos. As afinidades relativas à estrutura composicional, ao estilo e aos conteúdos temáticos são, a nosso ver, mais facilmente perceptíveis, já que se trata de gêneros discursivos do campo da argumentação. Quanto ao endereçamento, as afinidades são menos óbvias. Na resposta argumentativa, sobretudo quando solicitada em processos avaliativos, espera-se que os escreventes se dirijam ao docente, um outro/destinatário/interlocutor que representa a voz da instituição escolar. No artigo de opinião feito na disciplina de Leitura e Produção de Texto, o endereçamento é ambíguo por princípio: esperava-se que os escreventes se dirigissem a um outro/destinatário/interlocutor que representasse o leitor prototípico de um jornal local (endereçamento explicitado na tarefa a ser cumprida), mas está pressuposto, na dimensão pragmática dessa prática de escrita, que os escreventes também deveriam se dirigir a docente, um outro/destinatário/interlocutor que representa a voz da instituição escolar e é a responsável pela avaliação do texto - daí a afinidade com a resposta argumentativa. 
Por fim, o quarto tipo de negociação identificado de forma mais recorrente no conjunto de enunciados considerados para a análise mostra-se como alterações envolvendo diferentes e contraditórios posicionamentos.

Fig. 07 - Rasura digital: ponto de vista

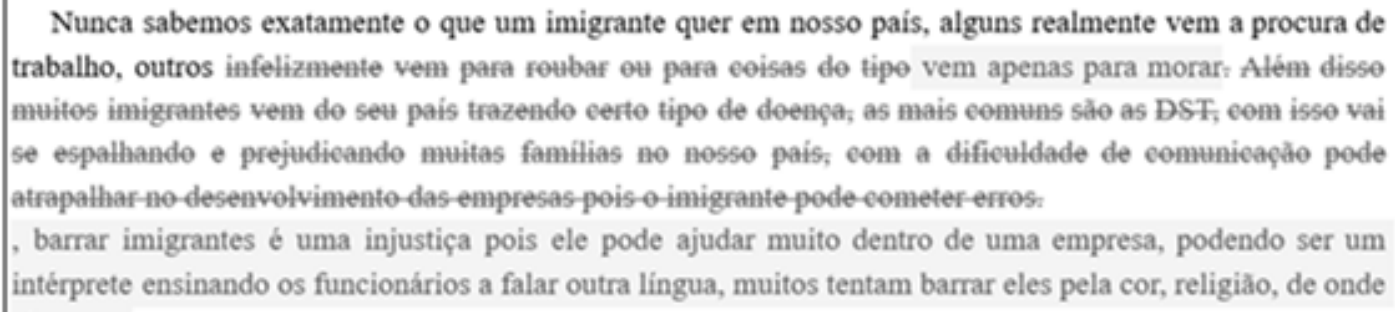
trabalho, outros infelizmente vem para reubar eu para eeisas de tipe vem apenas para morar Além disse muites imigrantes vem de seu pais trazende eerte tipe de deença; as mais eemuns sà̀ as DST, eөm isse vai se espalhande e prejudieande muitas familias ne nesse pais; eem a difieuldade de cemunieaçàe pode atrapalhar-no-desenvolvimento-das empresas pois-o imigrante pede-eemeter-erres: , barrar imigrantes é uma injustiça pois ele pode ajudar muito dentro de uma empresa, podendo ser um intérprete ensinando os funcionários a falar outra língua, muitos tentam barrar eles pela cor, religião, de onde ele vem.

Fonte: Banco de dados dos pesquisadores

Nesse excerto, o primeiro gesto de escrita dos escreventes produziu o seguinte enunciado:

Nunca sabemos exatamente o que um imigrante quer em nosso país, alguns realmente vem a procura de trabalho, outros infelizmente vem para roubar ou para coisa do tipo. Além disso muitos imigrantes vem do seu país trazendo certo tipo de doença, as mais comuns são as DST, com isso vai se espalhando e prejudicando muitas famílias no nosso país, com a dificuldade de comunicação pode atrapalhar no desenvolvimento das empresas pois o imigrante pode cometer erros (Transcrição do primeiro gesto de escrita)

Nesse enunciado, há uma tentativa de agenciar, no mínimo, duas vozes: uma que se insinua como relativamente favorável à presença de imigrantes no país, que pode ser vista em Nunca sabemos exatamente o que um imigrante quer em nosso país, alguns realmente vem a procura de trabalho e outra, explorada de forma mais robusta pelos escreventes, relativa ao restante do enunciado, que se coloca como enfaticamente desfavorável à presença de imigrantes no país. Essa posição desfavorável foi construída de forma frágil e os argumentos que a sustentam muito dificilmente encontrariam respaldo empírico e teórico são, portanto, argumentos nascidos de uma visão preconceituosa e estereotipada do que seja o imigrante e o efeito de sua presença no país onde se aloja. Essa fragilidade, no entanto, não invalida o fato de, do modo como foi elaborado esse primeiro enunciado, ser possível averiguar uma resposta direta às dimensões mostradas do artigo de opinião tal como ele foi solicitado pela docente, já que os escreventes conseguiram apresentar, pelo contraste, um ponto de vista sobre o tema: segundo esse enunciado, é legítimo barrar a imigração em nome da segurança e do desenvolvimento econômico do país. 
Esse enunciado é, entretanto, parcialmente deletado e, desse apagamento, vemos emergir a seguinte voz:

Nunca sabemos exatamente o que um imigrante quer em nosso país, alguns realmente vem a procura de trabalho, outros apenas para morar. barrar imigrantes é uma injustiça pois ele pode ajudar muito dentro da empresa, podendo ser intérprete, ensinando os funcionários a falar outra língua, muitos tentam barrar eles pela cor, religião e de onde ele vem. (Transcrição do segundo gesto de escrita).

Nessa alteração, há uma mudança de ponto de vista. Os escreventes abandonam o ponto de vista desfavorável e optam por assumir um nitidamente favorável, destacando o que parecem entender como benesses da presença de imigrantes no país. No contraste entre o primeiro e o segundo enunciado, que substitui o primeiro, mostra-se, a nosso ver, mais uma dimensão escondida das práticas letradas acadêmicas: a necessidade, não explicitada, de lidar com diferentes expectativas e discursos quando, num texto escrito pertencente a um processo avaliativo, os escreventes devem se posicionar sobre um tema considerando o enquadramento e o(s) leitor(es).

$\mathrm{Na}$ prática letrada aqui analisada, para posicionar-se em relação ao tema "imigração", os escreventes precisam considerar (a) o leitor real, no caso a docente, e os discursos legitimados por esse leitor, por meio das orientações e textos complementares que forneceu para a realização da atividade; (b) os possíveis discursos de um leitor superior, no caso da instituição; (c) os discursos dos próprios alunos que, numa atividade em grupo, se multiplicam de forma nem sempre convergente; (d) os discursos dos leitores imaginados para o artigo de opinião (os leitores de um jornal local), que os escreventes deveriam convencer. Não se trata, portanto, apenas de defender um ponto de vista sobre um tema, mas defender um ponto de vista em função da imagem que se faz sobre o que seria um ponto de vista aceito para esse gênero e pelos leitores real, virtual e superior, com suas singulares características.

\section{Essas reflexões não acabam aqui...}

Por meio da tentativa de estabelecer um diálogo que acreditamos profícuo entre pesquisas no campo dos Letramentos Acadêmicos e pesquisas cujo interesse é o de compreender o funcionamento de rasuras (manuscritas e digitais), neste artigo, nosso propósito mais geral foi responder a dois objetivos principais: identificar quais negociações se mostravam nas rasuras digitais presentes nos artigos de opinião redigidos por acadêmicos e avaliar em que medida essas negociações poderiam sinalizar dimensões escondidas das práticas letradas acadêmicas. Tendo como guia esses objetivos, vimos que, na busca por 
redigirem o artigo de opinião que julgavam ser o ideal - aquele legitimado pela docente por meio das orientações e dos textos complementares fornecidos com o intento de circunscrever o que seria um artigo de opinião - os acadêmicos realizaram várias idas e vindas, abandonando caminhos escolhidos, substituindo projetos de dizer... enfim, rasurando seu enunciado.

Pudemos verificar que as várias rasuras encontradas em nosso material de análise sinalizam uma ampla variedade de negociações, dentre as quais quatro se revelaram mais recorrentes: (a) ligadas à seleção do léxico; (b) ligadas à norma linguística; (c) ligadas ao enquadramento do gênero; e (d) ligadas aos posicionamentos sociais expressos nos textos. Nas rasuras, testemunhamos a negociação dos sujeitos escreventes ora com dimensões mostradas, mas opacas, como aquelas ligadas à norma linguística, cuja interpretação estava sempre na dependência dos sujeitos históricos que delas se apropriaram, nas condições sócio-históricas particulares em que foram mobilizadas; ora com dimensões escondidas das práticas letradas acadêmicas, como aquelas ligadas ao enquadramento do gênero e aos posicionamentos sociais expressos nos textos.

Essas dimensões mostradas, mas opacas, e as dimensões escondidas estiveram ligadas à possibilidade, sempre presente no processo de produção de textos, de outras palavras, outras normas, outros gêneros, outros posicionamentos conviverem com as palavras, normas, gêneros e posicionamentos acionados pela docente. Essa condição intrínseca do processo de produção de textos nos permite dizer, como defendem Lea e Street (1998), que, de fato, podem existir lacunas na forma como acadêmicos e docentes compreendem o processo de produção textual no nível da epistemologia, da autoridade e da contestação do conhecimento.

Ao nosso ver, essas lacunas são fruto da pluralidade de sentidos das relações de poder instituídas e reafirmadas, tanto pela docente, quanto pelos acadêmicos, na prática letrada aqui analisada. As rasuras examinadas neste artigo permitem sugerir que acadêmicos e docente têm representações que ora comungam, ora diferem da atividade avaliativa, da língua válida para essa atividade, dos contornos do gênero artigo de opinião específico daquela atividade avaliativa acadêmica, dos possíveis interlocutores. Essa oscilação nas representações nasce do fato de que acadêmicos e docente, embora circulem pela mesma prática, nem sempre dividem o conjuntamente visto, conjuntamente sabido e conjuntamente avaliado (VOLOCHINOV; BAKHTIN, 1926, p. 7).

\section{Referências}

ABAURre, M.; ABAURRE, M. B. M.; PONTARA, M. Português: contexto, interlocução e sentido. São Paulo: Editora Moderna, 2008. 
AUTHIER-REVUZ, J. Paradas sobre as palavras: a língua em prova na enunciação e na escrita. Educação e Realidade, v. 36, n. 3, p. 651-679, 2011.

AUTHIER-REVUZ, J. Palavras incertas: as não coincidências do dizer. Campinas: Editora da UNICAMP, 1998.

BAGNO, M. Língua, história e sociedade: breve retrospecto da norma-padrão brasileira. In: BAGNO, M. (org.). Lingüística da norma. São Paulo: Loyola, 2002, p. 179- 199.

BAKHTIN, M. M. Estética da criação verbal. São Paulo: Livraria Martins Fontes, 1992.

BARTON, D., HAMILTON, M., \& IVANIČ, R. Situated literacies: reading and writing in context. London: Psychology Press, 2000.

BIASI P. M. O horizonte genético. In: ZULLAR, R. (org.) Criação em processo: ensaios de crítica genética. São Paulo: Iluminuras, 2002, p. 219-244.

BIASI, P. Le cauchemar de Marcel Proust. Disponível em: http://www.item.ens.fr/index.php?id=187315. Acesso em: 05 jan. 2019.

CALIL, E.; FELIPETO, S. C. Entre o oral e o escrito: as posições de sujeito nas rasuras. Letras Hoje, 36(125), p. 347-353, 2001.

CÁLIS, O. G. T. Quando as memórias são a matéria: memoriais de professoras alfabetizadoras e instabilidade genérica. 2015, $303 \mathrm{f}$. Tese (Doutorado em Letras). Programa de Filologia e Língua Portuguesa. Universidade de São Paulo, São Paulo.

Capristano, C. C. Um entre outros: a emergência da rasura na aquisição da escrita. Linguagem em (Dis) curso, v. 13. n. 3, p. 667-694, 2013.

CERUTTI-RIZZATTI, M. E. Ensino de Língua Portuguesa e inquietações teórico-metodológicas: os gêneros discursivos na aula de Português e a aula (de Português) como gênero discursivo. Alfa, São Paulo, 56 (1): 249-269, 2012.

CORRÊA, M. L.G. As perspectivas etnográfica e discursiva no ensino da escrita: o exemplo de textos de pré-universitários. Revista da ABRALIN, v. 10, n. 4, p. 333-356, 2011.

CORRÊA, M. L.G. Relações intergenéricas na análise indiciária de textos escritos. Trabalhos em Linguística Aplicada, Campinas, v. 45, n. 2, p. 205-224, 2006.

CORRÊA, M. L.G. Linguagem \& Comunicação social: visões da lingüística moderna. São Paulo: Parábola Editorial, 2003.

CRISTÓVÃO, V. L. L. Gêneros textuais e educação inicial do professor de Língua Inglesa. Linguagem em (Dis)curso, Palhoça, SC, v. 10, n. 3, p. 705-734, set./dez. 2010

FIAD, R. S. A escrita na universidade. Revista da ABRALIN, Número Especial, p. 357-369, 2011.

GEE, J. P. Literacy, discourse and linguistics: introduction. Journal of education, v. 171, n. 1, p. 26-38, 1989.

Hilá, C. V. D. O gênero artigo de opinião: diagnóstico e intervenção na formação inicial de professores de português. Trabalhos em Linguística Aplicada , 47(1), 183-201, 2008.

IVANIČ, R. Writing and identity. Cidade? John Benjamins Publishing Company, 1998. 
KOMESU, F. C.; FISCHER, A. O modelo de "letramentos acadêmicos": teoria e aplicações. Filologia e Linguística Portuguesa, n. 16, v. 2, p. 477-493, 2014.

KOMESU, F.; GAMBARATO, R. R. Letramentos acadêmicos no ensino superior: aspectos verbo-visuais no processo de textualização em contexto semipresencial. Revista Linguagem \& Ensino, v. 16, n. 1, p. 15-38, 2013.

LEA, M. R.; STREET, B. V. Student writing in higher education: an academic literacies approach. Studies in higher education, v. 23, n. 2, p. 157-172, 1998.

LILLIS, T. Whose common sense? Essayist literacy and the institutional practice of mystery, in: C. JONES, J; TURNER; B. STREET (Eds) Student Writing. Cultural and Epistemological Issues. Amsterdam: Benjamins, 1999, p. 127-140.

MACHADO, T. H. S.; CAPRISTANO, C. C. Rasuras ligadas à segmentação de palavras na aquisição da escrita. Educação em Revista, v. 32, n. 1, p. 337-364, 2016.

MACHADO, T. H. S. Rasuras ligadas à segmentação de palavras na escrita infantil. 2014. 112 f. Dissertação (Mestrado em Letras) - Programa de Mestrado em Letras, Universidade Estadual de Maringá - UEM, Maringá, 2014.

MARINHO, M. A escrita nas práticas de letramento acadêmico. Revista brasileira de linguística aplicada, n. 10, v. 2, p. 363-386, 2010.

OHUSCHI, M. C. G.; BARBOSA, F. S. Gênero artigo de opinião: da teoria à prática em sala de aula. Acta Scientiarum. Language and Culture. Maringá, v. 33, n. 2, p. 303-314, 2011.

PASQUOTTE-VIEIRA, E. A. Letramentos acadêmicos: (re) significações e (re) posicionamentos de sujeitos discursivos (Tese de Doutorado). Universidade Estadual de Campinas, Campinas. Disponível em: http://bdtd.ibict.br/vufind/Record/CAMP, 2014.

PONZIO, A. A revolução bakhtiniana: o pensamento de Bakhtin. Contexto: São Paulo, 2016.

SILVA, M. I. L. Crítica genética na era digital: o processo continua. Letras de Hoje, n. 45, v. 4, p. 43-47, 2010.

STREET, B. V. Letramentos sociais: abordagens críticas do letramento no desenvolvimento, na etnografia e na educação. São Paulo: Parábola Editorial, 2014.

STREET, B. V. Dimensões "escondidas" na escrita de artigos acadêmicos. Revista Perspectiva. v. 28, n. 2, p. 541-567, 2010.

STREET, B. V. Literacy in theory and practice. New York. Cambridge University Press, 1984.

VOLOCHÍNOV, V. N.; BAKHTIN, M. Discurso na Vida e Discurso na Arte (sobre a poética sociológica). Trad. De Carlos Alberto Faraco e Cristóvão Tezza [para fins didáticos]. Versão da língua inglesa de I. R. Titunik, a partir do original russo, em 1926.

Recebido em: 18/02/2019

Aceito em: 13/06/2019 